\title{
Buckling phenomenon for imperfect pipe under pure bending
}

\author{
Hartono Yudo ${ }^{1,2} \cdot$ Takao Yoshikawa $^{3}$
}

\begin{abstract}
The buckling phenomenon for imperfect pipe under bending has been investigated by nonlinear FEA, considering the effect of a cross sectional oval deformation by changing the variables of pipes, that is, $L / D$ varying from 2.5 to $20, D / t$ varying from 50 to 200 , and imperfection $\left(\delta_{\mathrm{o}} / t\right)$ varying from 0.05 to 0.5 . As well as the elastic buckling, the elasto-plastic buckling was investigated. From the calculation results, the followings were found. The reduction of buckling moment due to imperfection is larger in short pipe than in long pipe. The effect of imperfection for pipes with large values of $D / t$ is larger than those with small values of $D / t$ if $L / D$ of both pipes is same. The effects of imperfection for elastic analysis are larger than elasto-plastic analysis. The buckling moment reduces more by the imperfection of buckling mode than by that of oval mode.
\end{abstract}

Keywords Imperfect pipe - Buckling moment - Oval deformation · Elastic buckling · Elasto-plastic buckling

$\begin{array}{ll}\text { Abbreviations } \\ D & \text { Diameter of cylinder } \\ E & \text { Young's modulus } \\ L & \text { Length of pipe } \\ M & \text { Applied moment }\end{array}$

Hartono Yudo

hartono.yudo@kyudai.jp

1 Department of Maritime Engineering, Graduate School of Engineering, Kyushu University, Fukuoka, Japan

2 Naval Architecture, Faculty of Engineering, Diponegoro University, Semarang, Indonesia

3 Department of Marine System Engineering, Faculty of Engineering, Kyushu University, Fukuoka, Japan
$M_{\mathrm{b}} \quad$ Buckling moment obtained by nonlinear calculation in elastic analysis

$M_{\text {cr }} \quad$ Critical bending moment

$M_{\text {cr1 }} \quad$ Critical bending moment, when the critical buckling stress of a cylinder under bending is same as the buckling stress of a cylinder under axial compression

$M_{\text {cr2 }} \quad$ Critical bending moment by Timoshenko

$M_{\mathrm{o}} \quad$ Maximum buckling moment in elastic analysis without imperfection

$M_{\mathrm{u}} \quad$ Ultimate moment in elasto-plastic analysis

$M_{\mathrm{Y}} \quad$ Initial yield moment

$\beta \quad$ Parameter $\beta=(D / t)\left(\sigma_{\mathrm{Y}} / E\right)$

$\delta \quad$ Amplitude of oval deformation

$\delta_{\mathrm{o}} \quad$ Maximum amplitude of imperfection

$v \quad$ Poisson's ratio

$\sigma_{\mathrm{cr}} \quad$ Critical buckling stress under axial compression

$\sigma_{\mathrm{Y}} \quad$ Yield stress

$M_{\mathrm{b}} / \quad$ Non-dimensional buckling moment in elastic

$M_{\text {cr1 }} \quad$ analysis

$M_{\mathrm{u}} / \quad$ Non-dimensional buckling moment in elasto-

$M_{\mathrm{Y}} \quad$ plastic analysis

\section{Introduction}

Buckling strength of pipe under bending was reduced due to a small value of geometrical imperfections. The pipe will lose its stability under certain value of the moment and become buckling.

The previous researches for estimating the buckling stress and the buckling moment of cylinder under bending are now briefly explained. 
If the critical buckling stress of a cylinder under bending is same as the buckling stress of a cylinder under axial compression, then the critical stress can be expressed by Eq. 1

$\sigma_{\mathrm{cr}}=\frac{E}{\sqrt{3\left(1-v^{2}\right)}}\left(\frac{t}{r}\right)$.

The maximum bending stress of a cylinder under the critical (buckling) moment $M_{\mathrm{cr}}$ can be expressed by Eq. 2 .

$\sigma_{\mathrm{cr}}=\frac{M_{\mathrm{cr}}}{\pi r^{2} t}$

where, $r$ is the pipe radius and $t$ is the wall thickness.

From Eqs. (1) to (2), using Poisson's ratio $(v)=0.3$, the critical moment can be estimated as follow.

$$
\begin{aligned}
M_{\mathrm{cr} 1} & =\sigma_{\mathrm{cr}} \cdot \pi r^{2} t \\
& =0.605 \pi E r t^{2} .
\end{aligned}
$$

Timoshenko and Gere [1] gave the statement that the maximum compressive stress at critical buckling moment is about $30 \%$ higher than the stress obtained from Eq. 1. Then, the buckling moment is given by Eq. 4 .

$$
\begin{aligned}
M_{\mathrm{cr} 2} & =1.3 \times M_{\mathrm{cr} 1} \\
& =0.787 \pi E r t^{2} .
\end{aligned}
$$

The numerical calculation results using FEA by authors [2] for straight pipe, whose $L / D$ is varying from 5 to 20 and $D / t$ varying from 50 to 200 , showed that the critical bending moment in linear calculation is expressed by Eq. 5.

$$
\begin{aligned}
M_{\mathrm{cr} 3} & =1.1 \times M_{\mathrm{cr} 1} \\
& =0.666 \pi E r t^{2} .
\end{aligned}
$$

Seide and Weingarten [3] solved this as a bifurcation buckling problem. Assuming that the pre-buckling behavior can be defined with sufficient accuracy by a linear membrane solution, they found that the critical buckling stress is only $1.5 \%$ higher than Eq. 1, for a cylinder with $r / t=100$. For thinner cylinders, the difference is even smaller.

Odland [4] calculated that the collapse moment of cylinder with $R / t=100$ and showed that the collapse moment of cylinder with $L / D=5,10$, and infinity is ab.70, 60 , and $50 \%$ of $M_{\mathrm{cr} 1}$, respectively, because of oval deformation of a section.

$\mathrm{Ju}$ and Kyriakides [5] mentioned that oval deformation reduces the bending rigidity and leads to a limited load instability associated with local collapse.

In the previous research by authors [6] for straight pipes under pure bending moment, the nonlinear FEA considering the effect of the cross-sectional oval deformation was performed by changing the scantling of pipes. In this study, the length-to-diameter ratio $L / D$ varies from 5 to 20 , and $D / t$ varies 50 to 200 . From the numerical results, the maximum moment for long pipe considering oval deformation is shown as follow:

$M_{\max }=0.52 M_{\mathrm{cr} 1}=0.314 \pi E r t^{2}$.

The initial yield moment of a pipe under bending is shown below.

$M_{\mathrm{Y}}=\sigma_{\mathrm{Y}} \pi \cdot r^{2} \cdot t$,

where, $\sigma_{\mathrm{Y}}$ is the yield stress.

SUPERB [7] outlined the geometrical imperfections (excluding corrosion) that are normally allowed in pipeline design will not exert a significant influence on the maximum strength of the pipe, and the buckling moment in the plastic region can be calculated as:

$M_{\mathrm{p}}=\left(1.05-0.003 \cdot \frac{r}{t}\right) \cdot \sigma_{\mathrm{Y}} \cdot D^{2} \cdot t$.

If $r / t$ equals to 50 , Eq. (8) becomes

$M_{\mathrm{p}}=1.14 \cdot \sigma_{\mathrm{Y}} \pi \cdot r^{2} \cdot t$.

The ultimate moment in Eq. 9 is only $14 \%$ higher than the initial yielding moment.

The buckling moment of a pipe is much reduced due to the imperfections. In the previous researches, the buckling moment of perfect pipe under bending has been investigated and some formulas have presented. But, the comprehensive study on the buckling moment of pipe with initial imperfection under bending has not been found.

In this study, the series calculations of buckling and collapse strength of a pipe under bending with initial imperfection were performed by utilizing nonlinear FE software.

\section{Procedures of calculation for estimating nonlinear buckling moment of imperfect pipe under bending}

\subsection{Parameters for calculation}

In calculation of a pipe, the ratio of length-to-diameter $(L / D)$ and the ratio of diameter to thickness $(D / t)$ are taken as the calculation parameters. $L / D$ varies from 2.5 to 20 , in which the diameter is changing from 1000 to $4000 \mathrm{~mm}$. And $D / t$ varies from 50 to 200 . Where, $D$ is the pipe diameter, $t$ is the wall thickness, and $L$ is the pipe length as shown in Table 1.

In calculation of the elasto-plastic analysis for imperfect pipe under pure bending, the yield stress of material assumed to be $621 \mathrm{MPa}$. The elasto perfect plastic material is chosen in the numerical analysis. It means strength hardening after yielding has not been considered. 
Table 1 The parameters for calculating the nonlinear buckling moment of pipe under pure bending

\begin{tabular}{llrl}
\hline Cases & $D(\mathrm{~mm})$ & $D / t$ & $L / D$ \\
\hline I & 1000 & 50 & $2.5-20$ \\
II & 2000 & 100 & $2.5-20$ \\
III & 4000 & 200 & $2.5-20$ \\
\hline
\end{tabular}

\subsection{Model for calculation and calculation program}

The full length models of pipes with imperfection are used in FEA as shown in Fig. 1. The nonlinear buckling calculations of pipe under pure bending are performed. In this model, the initial imperfection of buckling mode, which can be obtained by linear buckling calculation for perfect pipe as shown in Fig. 2, is introduced.

General purpose FE software MSC Marc is used for the nonlinear buckling analysis in which the oval deformation of cross section before buckling is taken account. The quadrilateral 4 node element (No. 75) is used. The calculating region is divided into 36 elements in circumferential direction. The element number in length is basically 120 and more elements are used to maintain the calculation accuracy in the case of long cylinder. The convergence of calculation by mesh division was confirmed in previous research.

\subsection{Boundary conditions and loading conditions}

The cylindrical coordinates are used. The boundary conditions $U_{\mathrm{Z}}=0$ are given at the mid span of the cylinder and $U_{\ominus}=0$ at four points as shown in Fig. 3 .

The rigid body elements (RBE) are inserted at both end sections in order to connect the center of circle and the points on circle as shown in Fig. 3. The bending moment is loaded at the center of circle at both ends. The rigid body elements (RBE) prevent the oval deformation of both end section, and keep the section in plane under rotational deformation by bending moment. In MSC Marc, a rigid link for either small deformation or large deformation can be implemented using RBE.

Fig. 1 The full length model of pipe

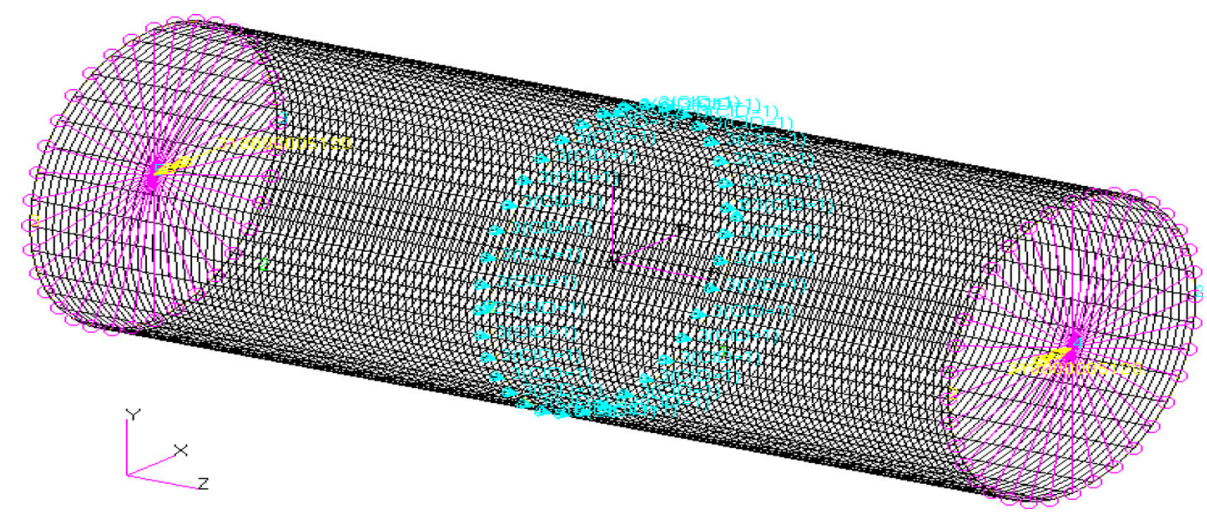

Fig. 2 The initial imperfection of buckling mode

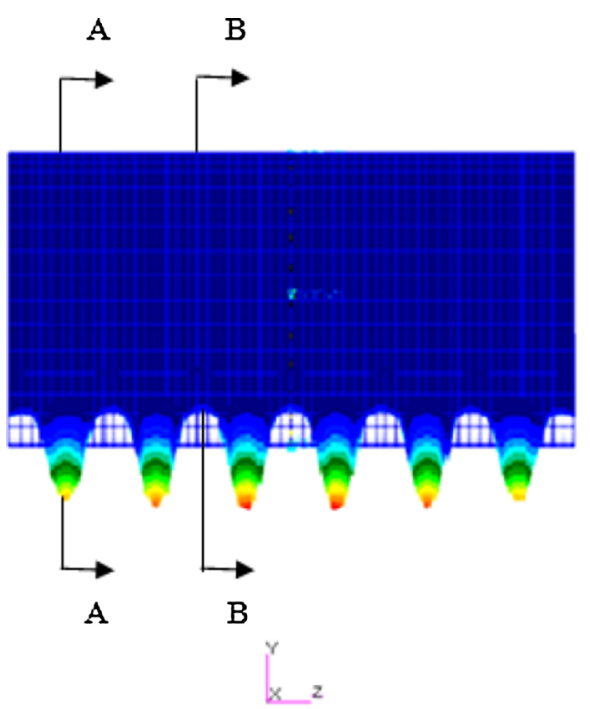

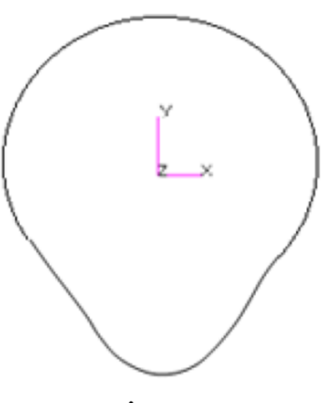

Section A - A

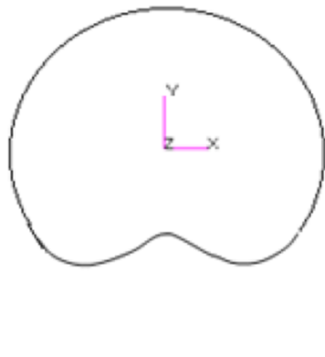

Section B - B 
Fig. 3 Boundary condition at mid span section and end sections

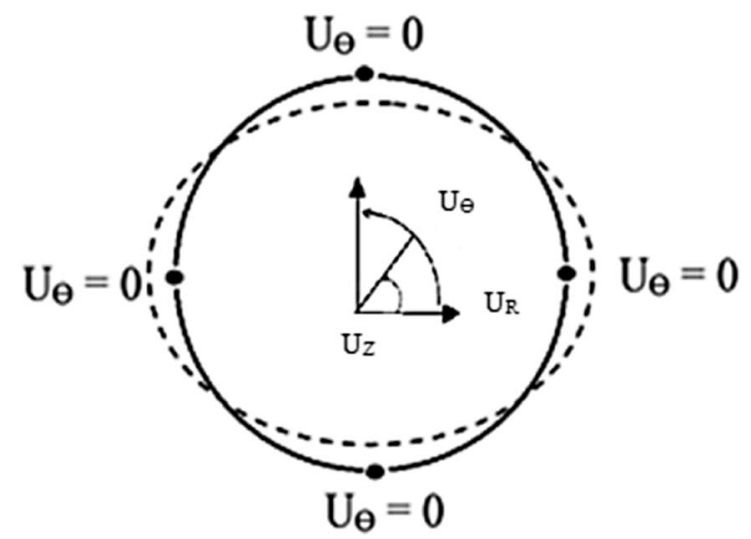

Mid span section

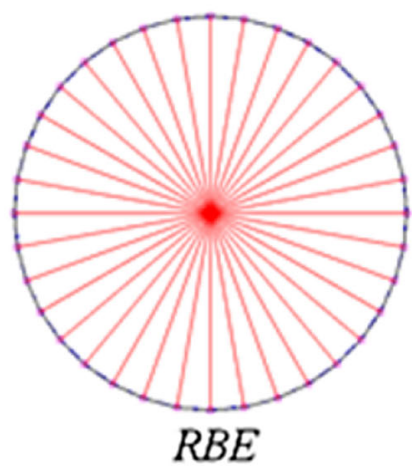

Ends section

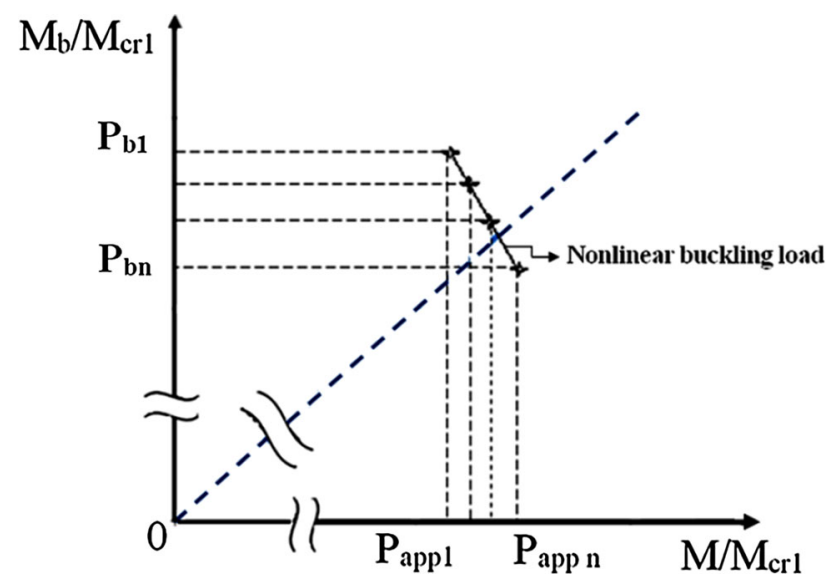

Fig. 4 Schematic diagram for estimation of bifurcation moment

\subsection{Method to obtain bifurcation moment in nonlinear calculation}

To obtain the bifurcation buckling moment and its mode, the eigenvalue calculations are performed at the proper load increment, and the point at which the buckling moment and the applied moment become a same vales is defined as the bifurcation buckling moment, as shown in the schematics in Fig. 4. In this figure, the vertical axis shows the bifurcation buckling eigenvalue, and the horizontal axis shows the applied load.

The eigenvalue is calculated at each load increment considering the pre-buckling deformation. Therefore, the eigenvalue will change in response to the pre-buckling deformation. The bifurcation buckling load is judged as follows. When the value of the eigenvalue is larger than the applied load, buckling does not occur. Furthermore, when the eigenvalue is smaller than that of the applied load, the buckling has already happened. The intersection point of eigenvalues, and the applied load is treated as a bifurcation

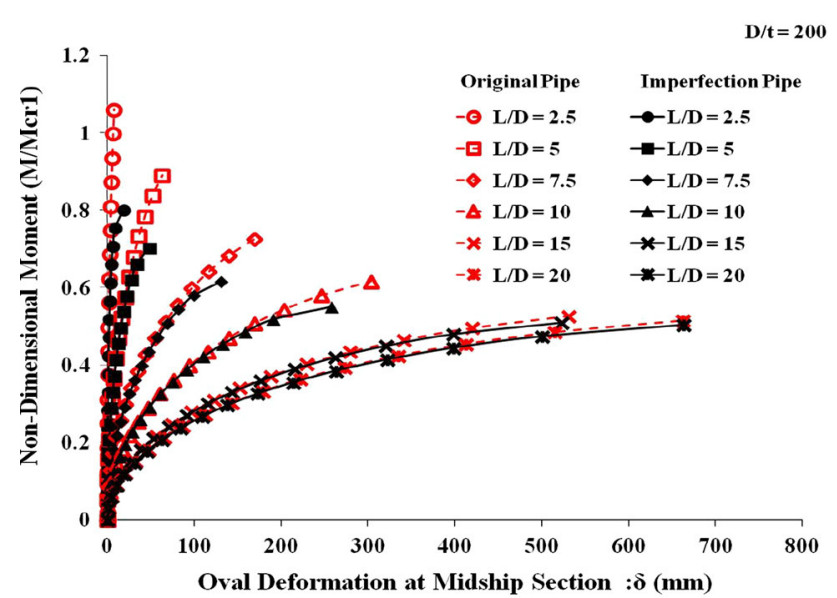

Fig. 5 The relationship between applied moment and oval deformation at mid span for original pipe and imperfect pipe of buckling mode $\delta_{\mathrm{O}} / t=0.05$ (elastic analysis, $D / t=200$ )

buckling load. Oval deformation will increase when the applied moment increases. Then, the bending rigidity of pipe will decrease and the curvature radius of mid span section will increase. As a result, the eigenvalue will decrease gradually.

\section{The numerical results on nonlinear buckling moment of imperfect pipe under pure bending}

Figure 5 shows the relationship between the applied bending moment and the oval deformation at mid span when the pipe behaves elastically. The vertical axis shows the non-dimensional moment $\left(M / M_{\mathrm{crl}}\right)$. The dotted lines with red color are calculation results for pipes without imperfection, and the solid lines with black color are calculation results for pipes with imperfection of buckling mode $\delta_{\mathrm{o}} / t=0.05$. The maximum moment of each curve 


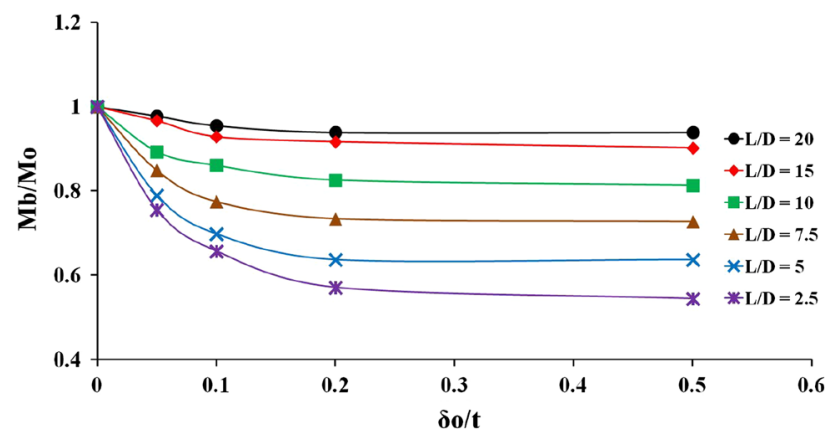

Fig. 6 The relationship between the buckling moment and the imperfection for pipe $D / t=200$ in elastic analysis

shows the bifurcation buckling moment. The buckling moment for imperfect pipe is lower than original pipe.

In long pipe, such as $L / D=10,15$, and 20 , the oval deformation increases much with increasing the applied load. On the other hand, in short pipe, such as $L / D=2.5$ and 5.0, the oval deformation is small by the restriction of sectional deformation at both ends. Due to the oval deformation before buckling at mid span, the buckling moment of long pipes reduced more compared to the short pipes.

Figure 6 shows the relationship between the buckling moment $\left(M_{\mathrm{b}} / M_{\mathrm{o}}\right)$ and the imperfection $\left(\delta_{\mathrm{o}} / t\right)$ for pipes $D / t=200$ when the pipes behave elastically. It is shown that the buckling moment decreases due to increase of imperfection. The effect of imperfection for shorter pipes such as $L / D=2.5$ and 5.0 is great. On the other hand, the imperfection has a smaller effect on the buckling moment for longer pipes. From Fig. 6, it can be seen that the effect of imperfection on the buckling moment is great in shorter pipes.

Figure 7 shows the oval deformation just before buckling at the mid span for pipe $D / t=200$ and $L / D=2.5$. Where, figure (a) perfect pipe without bending load, (b) perfect pipe under bending load, (c) imperfect pipe $\delta_{\mathrm{o}} / t=0.05$ under bending load, (d) imperfect pipe $\delta_{\mathrm{o}} / t=0.1$ under bending load, and (e) imperfect pipe $\delta_{\mathrm{o}} / t=0.2$ under bending load, respectively. The buckling mode grows at the pre-buckling stage in imperfect pipe as shown in Fig. 7c-e. Therefore, the buckling moment was reduced much by imperfection.

Figure 8 shows the oval deformation just before buckling at the mid span for pipe $D / t=200$ and $L / D=20$. Where, figure (a) perfect pipe without bending load, (b) perfect pipe under bending load, (c) imperfect pipe $\delta_{\mathrm{o}} / t=0.05$ under bending load, (d) imperfect pipe $\delta_{\mathrm{o}} / t=0.1$ under bending load, and (e) imperfect pipe $\delta_{\mathrm{o}} / t=0.2$ under bending load, respectively. The oval deformation is dominant as shown in Fig. 8b-e. Contrary to the short pipe like Fig. $7 \mathrm{c}-\mathrm{e}$, the buckling mode does not

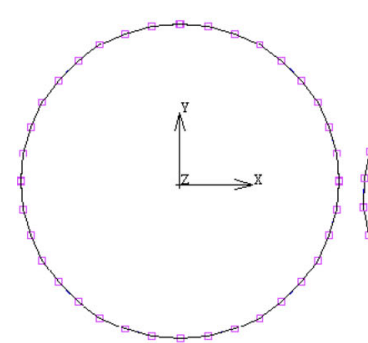

(a)

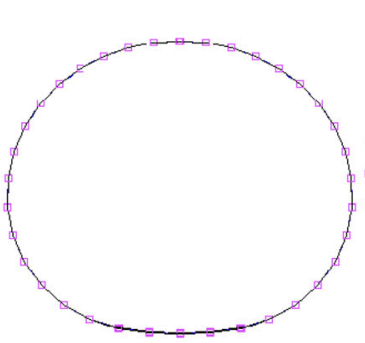

(b)

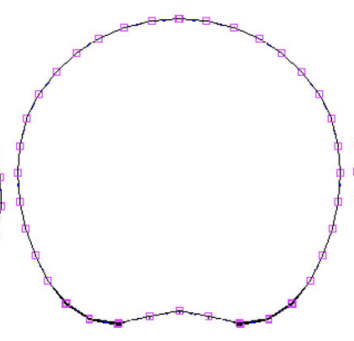

(c)

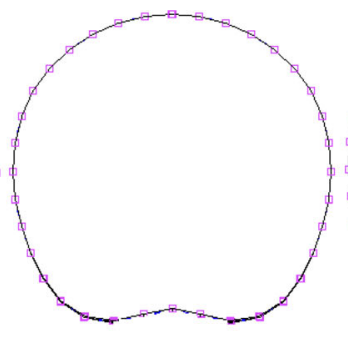

(d)

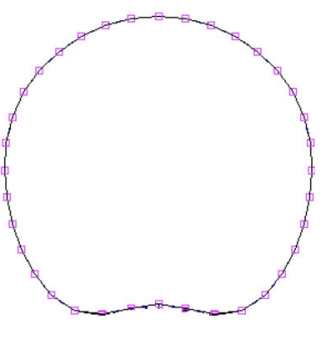

(e)

Fig. 7 The oval deformation just before buckling at the mid span for pipe $D / t=200$ and $L / D=2.5$. Where, figure a perfect pipe without bending load, b perfect pipe under bending load, c imperfect pipe

$\delta_{\mathrm{O}} / t=0.05$ under bending load, $\mathbf{d}$ imperfect pipe $\delta_{\mathrm{o}} / t=0.1$ under bending load, and e imperfect pipe $\delta_{\mathrm{o}} / t=0.2$ under bending load

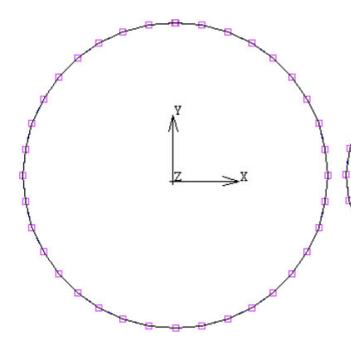

(a)

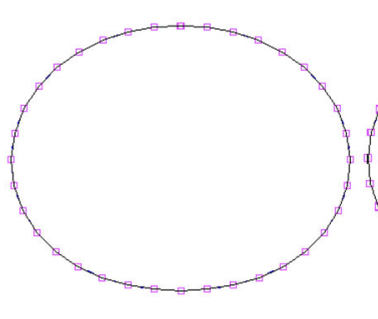

(b)

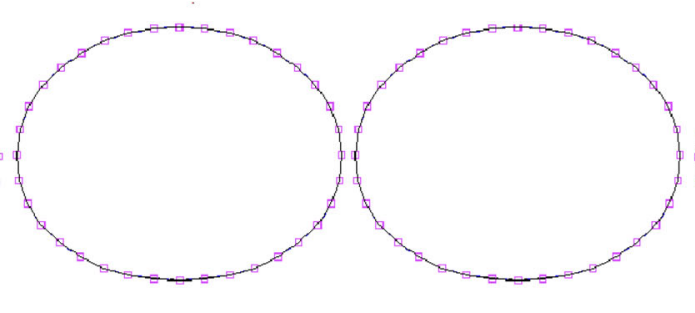

(c) (d)

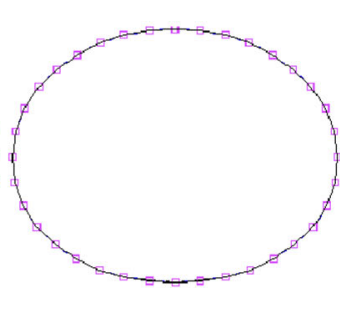

(e)

Fig. 8 The oval deformation just before buckling at the mid span for pipe $D / t=200$ and $L / D=20$. Where, figure a perfect pipe without bending load, b perfect pipe under bending load, $\mathbf{c}$ imperfect pipe

$\delta_{\mathrm{o}} / t=0.05$ under bending load, $\mathbf{d}$ imperfect pipe $\delta_{\mathrm{o}} / t=0.1$ under bending load, and e imperfect pipe $\delta_{\mathrm{o}} / t=0.2$ under bending load 


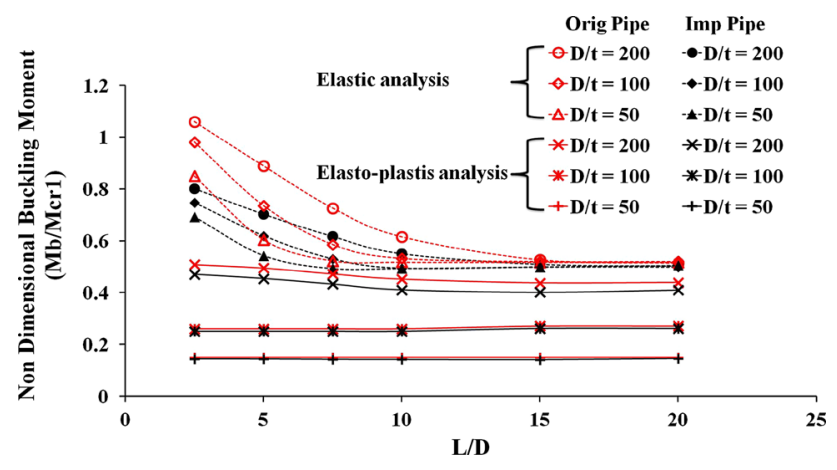

Fig. 9 The relationship between the buckling moment and $L / D$

grow before buckling. Therefore, the buckling moment of imperfect pipe was almost the same as that of perfect pipe in long cylinder.

Figure 9 shows the relationship between the non-dimensional buckling moment $\left(M_{\mathrm{b}} / M_{\mathrm{cr} 1}\right)$ and $L / D$. The red curves are the numerical results for pipe without imperfection, and the black curves are the numerical results for pipe with imperfection of buckling mode $\delta_{\mathrm{o}} / t=0.05$. The dotted curves are the elastic numerical results, and the solid curves are the elasto-plastic numerical results. In elastoplastic analysis, the yield stress of material is set to $621 \mathrm{MPa}$.

In elastic analysis, the buckling moment decreases with increasing length of pipe and becomes constant in the longer pipes. As mentioned above, the buckling moment reduces more in shorter pipes than longer pipes due to imperfection. In the longer pipes, the buckling moment is only $3 \%$ lower than the original pipe due to the imperfection of $\delta_{\mathrm{o}} / t=0.05$, where the buckling moment for the original long pipe is as shown by Eq. 10.

In elasto-plastic analysis, the effect of imperfection is smaller than in elastic analysis. Moreover, the buckling moments of all length of pipes with same $D / t$ are almost same, because the maximum buckling moments are limited by yielding.

Next, the effect of imperfection on buckling moment is examined by changing $D / t$ for short pipe such as $L / D=2.5$.

Figure 10 shows the relationship between the applied bending moment and the oval deformation at the mid span for perfect pipe with a value of $L / D=2.5$ and a value of $D / t$ varying from 50 to 200 when the pipe behaves elastically. When decreasing the value of $D / t$, the oval deformation at the mid span increases. The relationship between the applied bending moment and the oval deformation at the mid span for imperfect pipe is similar to that of perfect pipe.

Figure 11 shows the relationship between the maximum buckling moment $\left(M_{\mathrm{b}} / M_{\mathrm{o}}\right)$ and the magnitude of imperfection $\left(\delta_{\mathrm{o}} / t\right)$, for the pipes with different values of

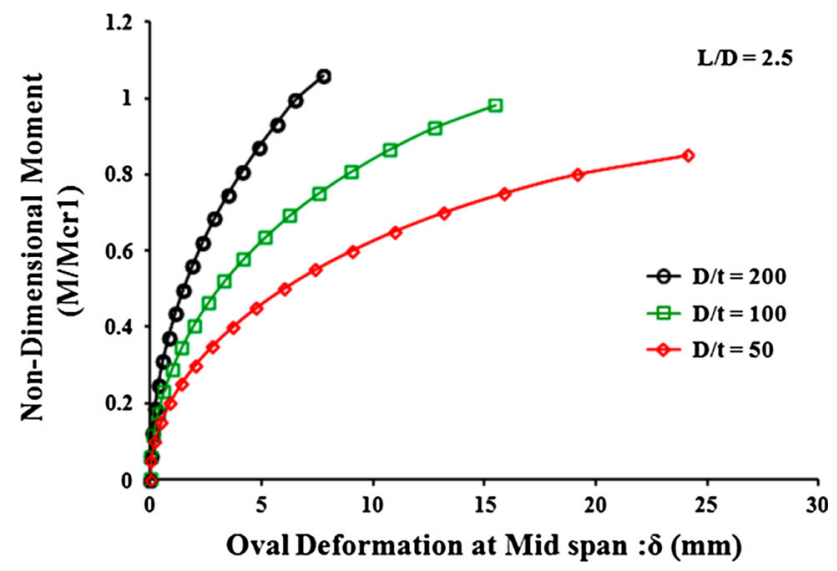

Fig. 10 Ovalization at the mid span for pipe $(L / D=2.5$ and $D / t=50-200)$ in elastic analysis

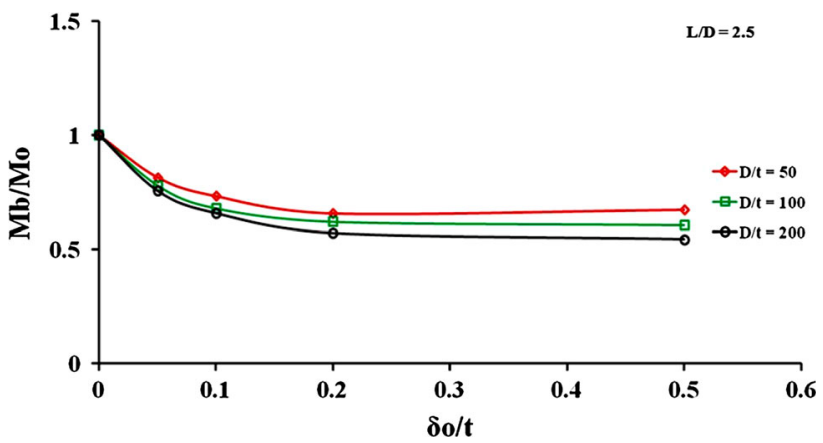

Fig. 11 Relationship between the maximum buckling moment and the imperfection of buckling mode for pipe $L / D=2.5$ in elastic analysis

$D / t$ when pipes behave elastically. This figure shows the effect of imperfection for pipes with large values of $D / t$ is little bit larger than those with small values of $D / t$.

From Figs. 10 and 11, it can be said that the effect of imperfection is great when the oval deformation before buckling is small.

Figure 12 shows the relationship between the non-dimensional buckling moment $\left(M_{\mathrm{b}} / M_{\mathrm{cr} 1}\right)$ and $D / t$ in elastic calculation. The numerical calculation results for perfect pipe are plotted with solid lines, and the numerical calculation results for imperfect pipes with $\delta_{\mathrm{o}} / t=0.05$ are plotted with dotted lines. For the pipe with a small value of $D / t$, the difference of the buckling moment between perfect and imperfect pipe is small. On the other hand, for the pipe with large value of $D / t$, the difference is large. The effect of imperfection on buckling moment of pipe in elastic analysis with small value of $D / t$ is smaller than pipe with large value of $D / t$ as shown in Fig. 12.

Figure 13 shows the effect of imperfection on the buckling moment comparing the imperfection of the buckling mode and the oval mode. Figure 14 shows the 


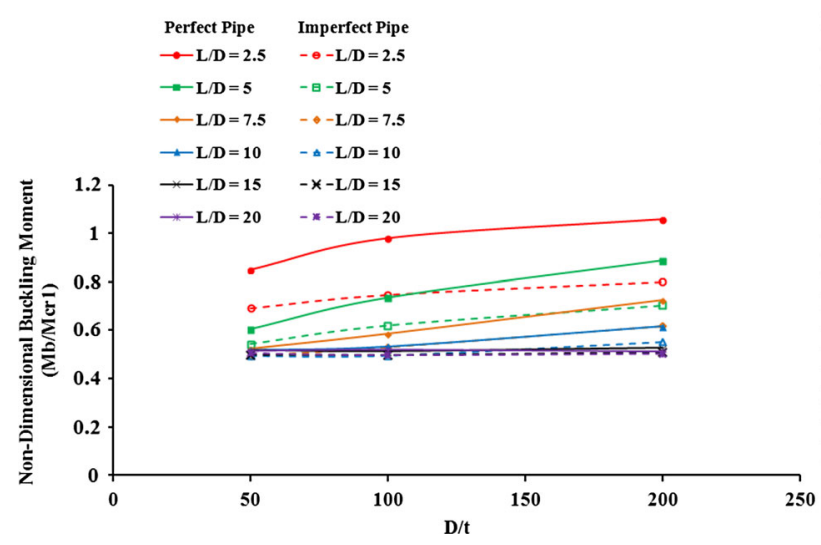

Fig. 12 The relationship between the buckling moment and $D / t$ in elastic analysis $\left(\delta_{\mathrm{o}} / t=0.05\right)$

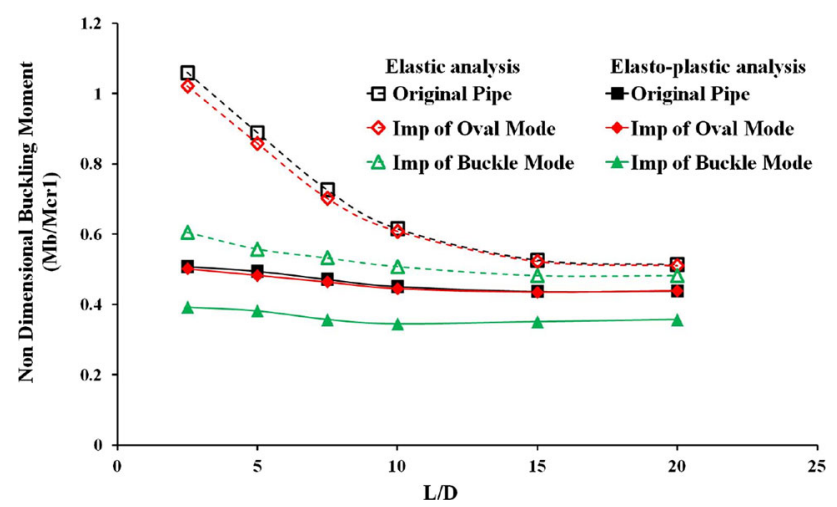

Fig. 13 The effect of imperfection on the buckling moment comparing the imperfection of the buckling mode and the oval mode $\delta_{\mathrm{o}} / t=0.2$

initial imperfection of oval mode. In Fig. 13, the elastic numerical results are plotted with dotted curves, and the elasto-plastic numerical results are plotted with solid curves. The curve with a rectangular marker is the original pipe, the curve with diamond marker is the pipe with the imperfection of the oval mode $\delta_{\mathrm{o}} / t=0.2$, and the curve with a triangle marker is the pipe with the imperfection of the buckling mode $\delta_{\mathrm{o}} / t=0.2$.
The effects of the imperfections of buckling modes on the buckling moment are larger than the effects of imperfections of the oval mode. The imperfection of the buckling mode reduces the buckling moment more than the imperfection of the oval mode, especially for the pipe with a small $L / D$.

In order to investigate the yielding effect on the buckling moment of pipe in bending, the non-dimensional parameter $(\beta)$ shown below is considered.

$\beta=(D / t)\left(\sigma_{\mathrm{Y}} / E\right) \infty\left(M_{\mathrm{crl} 1} / M_{\mathrm{Y}}\right)$.

This parameter is proportion to the ratio of the linear buckling moment and the initial yielding moment. The elasto-plastic buckling moment is examined by changing the yield stress and the diameter.

Figures 15 and 16 shows the relationship between the buckling moment and the imperfection $\left(\delta_{\mathrm{o}} / t\right)$ for the pipes of $L / D=2.5$ and 20 , respectively. The maximum moment is expressed non-dimensionally by dividing with the initial yielding moment $\left(M_{\mathrm{Y}}\right)$.

The solid curves with triangle, diamond, and rectangular marker are the numerical results for the pipes of $D / t=200$, whose yield strength are $\sigma_{\mathrm{Y}}=157.5,315$, and $621 \mathrm{MPa}$, where $\beta$ equals to $0.15,0.3$, and 0.6 , respectively. The dotted curves with triangle, diamond, and rectangular marker are the numerical results for the pipes of $D / t=50$, whose yield stress is $\sigma_{\mathrm{Y}}=621,1260$, and $2520 \mathrm{MPa}$, where $\beta$ equals to $0.15,0.3$, and 0.6 , respectively. Although some of above yield stresses are not realistic, these are used for showing the validity of parameter $\beta$.

When $\beta$ is large, the pipe buckles elastically. And when $\beta$ is small, the pipe buckles plastically. The non-dimensional buckling moment with imperfection decreases with increasing the value of $\beta$. And, the non-dimensional buckling moments is almost the same for the same value of $\beta$. Therefore, the parameter of $\beta$ is possible to be the parameter which represents the yielding effect on buckling moment of pipe with imperfection under bending. The effect of imperfection on buckling in plastic range is smaller than in elastic range.

Fig. 14 The initial imperfection of oval mode

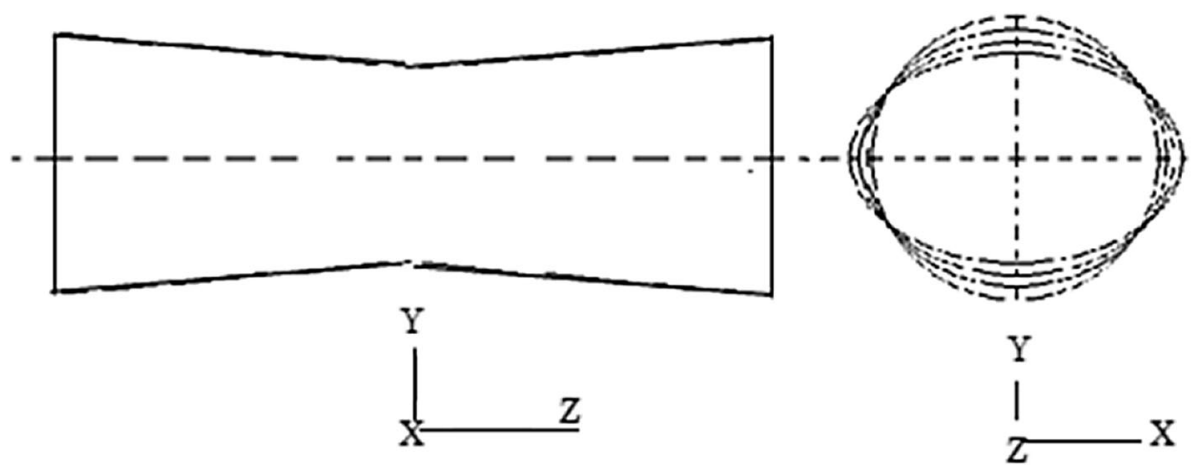




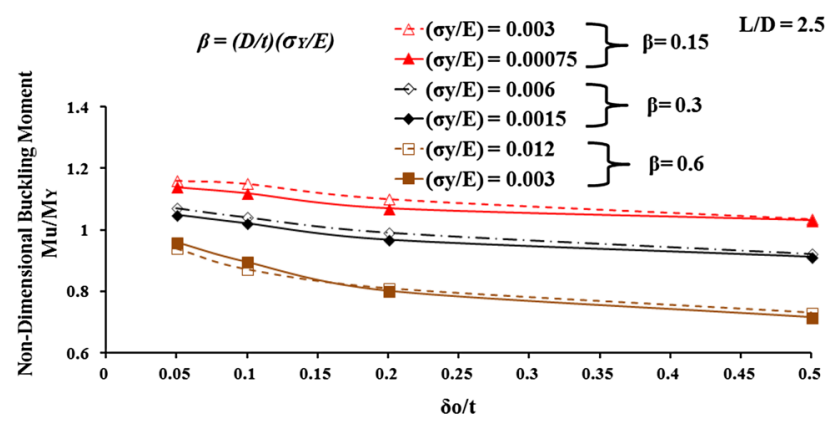

Fig. 15 The relationship between the buckling moment and the imperfection $\left(\delta_{\mathrm{o}} / t\right)$ for the pipes of $L / D=2.5$ in elasto-plastic analysis

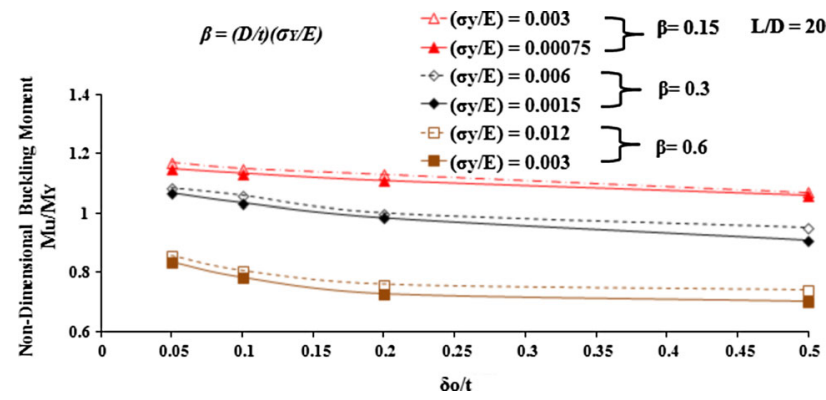

Fig. 16 The relationship between the buckling moment and the imperfection $\left(\delta_{\mathrm{o}} / t\right)$ for the pipes of $L / D=20$ in elasto-plastic analysis

In this paper, the calculation results are only shown for the pipes of $L / D=2.5$ and 20 . For the pipe with deferent $L / D$, using the same procedure, we can estimate the buckling moment like Figs. 15 and 16.

\section{Conclusions}

It is well known that the buckling moment of pipe decreases with increasing imperfection. In this study, the series calculations of buckling and collapse strength of pipes with initial imperfection under bending are performed by utilizing nonlinear $F E$ software.

The followings are clarified by the numerical calculation.

In elastic analysis, the buckling moment reduced more in longer pipes than in shorter pipes due to pre-buckling oval deformation. However, the reduction of buckling moment due to imperfection is greater in shorter pipes than in longer pipes. In the longer pipes, the buckling moment is only $3 \%$ lower than the original pipe due to the imperfection of $\delta_{\mathrm{o}} / t=0.05$.

The reduction of buckling moment due to imperfection is a little bit greater in the case of larger $D / t$ than in that of smaller $D / t$. This is because the oval deformation before buckling in the case of smaller $D / t$ is larger than that in cases of larger $D / t$.

As with the perfect pipe, the buckling moment of the imperfect pipe in elasto-plastic analysis is lower than in elastic analysis. The buckling moment is almost constant regardless of the pipe length for pipes with same value of $D / t$, because the maximum bending moment is limited by yielding.

The effect of the imperfection of buckling modes on the buckling moment is larger than that of the oval mode. In other words, the buckling moment reduces more due to the imperfection of buckling mode than by that of oval mode.

It is possible to see the parameter of $\beta=(D / t)\left(\sigma_{\mathrm{Y}} / E\right)$ as the parameter which represents the yielding effect on buckling moment of a pipe under bending for the case of the imperfect pipe. When $\beta$ is large, the pipe buckles elastically. And when $\beta$ is small, the pipe buckles plastically. In this paper, the elasto-plastic buckling moments for the imperfect cylinder with $\mathrm{L} / \mathrm{D}=2.5$ and 20 were shown. For the pipe with deferent $L / D$, the elasto-plastic buckling moments of imperfect pipes will be able to estimate with using same procedure.

\section{References}

1. Timoshenko S, Gere J (1961) Theory of elastic stability, 2nd edn. McGraw-Hill International Book Company

2. Yudo H, Yoshikawa T (2012) Mechanical behaviour of pipe under pure bending load. In: Proceedings of the 26th Asian technical exchange and advisory meeting on marine structures, pp 359-364

3. Seide P, Weingarten VI (1961) On The buckling of circular cylindrical shells under pure bending. Trans ASME J Appl Mech 28:112-116

4. Odland J (1978) Buckling resistance of unstiffened and stiffened circular cylindrical shell structures. Nor Marit Res 6(3):2-21

5. Ju GT, Kyriakides S (1992) Bifurcation and localization instabilities in cylindrical shells under bending: part II predictions. Int $\mathrm{J}$ Solids Struct 29:1143-1171

6. Yudo H, Yoshikawa T (2014) Buckling phenomenon for straight and curved pipe under pure bending. J Mar Sci Technol 20(1):94-103

7. SUPERB (1996) Buckling and collapse limit state, December 1996 